\title{
Ovarian Malignant Mesothelioma
}

National Cancer Institute

\section{Source}

National Cancer Institute. Ovarian Malignant Mesothelioma. NCI Thesaurus. Code

C40444.

A rare malignant mesothelial neoplasm that usually involves both the ovarian surface and the ovarian stroma. In most cases there is bilateral ovarian involvement. 